Boletín de la Sociedad Geológica Mexicana

VOLUMen 63, NÚM. 3, 2011, P. 487-501

\title{
Análisis geológico y aeromagnético de las concentraciones anómalas de Fe en el plutón San Jerónimo en el Cinturón Batolítico Peninsular, Baja California, México
}

\author{
Xóchitl G. Torres Carrillo ${ }^{1, *}$, Luis A. Delgado Argote ${ }^{1}$, Juan M. Espinosa Cardeña ${ }^{1}$, \\ José M. Romo Jones ${ }^{1}$ \\ ${ }^{1}$ División de Ciencias de la Tierra, CICESE, Ensenada, B.C., México, 22860 \\ *xtorres@cicese.mx
}

\begin{abstract}
Resumen
El plutón San Jerónimo forma parte de la zona oeste del Cinturón Batolítico Peninsular. El plutón cubre un espectro de litologías que varía desde gabro hasta granito. Rasgos curvilíneos interpretados de imágenes satelitales están asociados a la geometría de emplazamiento de las rocas intrusivas. Existe una correlación estrecha entre las fracturas longitudinales verticales con la foliación magmática, ambas orientadas NE-SW, que, se infiere, guardan relación con estructuras de emplazamiento. De acuerdo con la proporción de rocas máficas/félsicas, el plutón San Jerónimo se dividió en las zonas norte y sur. En la zona norte dominan rocas gabróicas y dioríticas con alto contenido de magnetita diseminada; en las tonalitas de la misma zona es notable la existencia de diques con concentraciones aproximadas de $90 \%$ de óxidos de Fe. En la zona sur, las rocas máficas y félsicas guardan la misma proporción y el contenido de magnetita disminuye considerablemente. La susceptibilidad magnética varía en función del contenido de magnetita y, en consecuencia, la intensidad de las anomalías magnéticas es mayor en la zona norte que en la sur. Los valores más altos de intensidad de campo magnético en la zona norte están asociados con la presencia de los diques de óxidos de fierro. Se interpreta que los diques son producto de la concentración de magnetita en los magmas máficos por efecto de inmiscibilidad y que su emplazamiento ocurrió en estado sólido al ser empujado por el cuerpo félsico más joven durante su movimiento ascendente.
\end{abstract}

Palabras clave: plutón San Jerónimo, Cinturón Batolítico Peninsular, anomalías magnéticas, magnetita.

\begin{abstract}
The San Jerónimo pluton belongs to the Peninsular Ranges Batholith. The modal composition indicates lithologies ranging from gabbro to granite. Curvilinear features interpreted from satellite images are related to the emplacement geometry of the pluton, and are less evident in the low viscosity mafic rocks. Because of the close relationship to the movement of magma, NE-SW oriented longitudinal fractures are closely parallel to magmatic foliation. The pluton is divided into the northern and southern zones based on the mafic/ felsic rock ratio. In the northern part, magnetite-rich gabbro and diorite are dominant, and minor tonalite is characterized by its association with dikes with concentrations of more than 90\% magnetite. In the southern part, mafic and felsic rocks show almost the same proportion and magnetite content diminishes. As expected, the magnetic susceptibility varies according to the magnetite content; in consequence, the intensity in the northern part is higher, and is directly associated to the presence of the magnetite-rich dikes. It is interpreted that the magnetite dikes result from early concentrations due to immiscibility in the mafic liquids, and that solid-state emplacement was induced by the younger felsic magma during its ascent.
\end{abstract}

Keywords: San Jeronimo pluton, Peninsular Ranges Batholiths, magnetic anomalies, magnetite. 


\section{Introducción}

El Cinturón Batolítico Peninsular es parte de un arco magmático asociado a una margen convergente. El conjunto de rocas plutónicas, expuesto desde el sur de California, EE.UU., hasta la mitad de la península de Baja California, incluyendo la región de la península de Vizcaíno, tal vez sea el cinturón plutónico mejor expuesto en México. En él se observan rocas pertenecientes a tres arcos magmáticos (Chávez-Cabello, 1998). El más occidental es del Jurásico y aflora ampliamente en la península de Vizcaíno, seguido hacia el oriente por los complejos batolíticos tipo I (ricos en magnetita) asociados al Arco Alisitos del Cretácico Temprano a Tardío y, el más oriental, formado por rocas graníticas tipo S (ricas en ilmenita) del Cretácico Tardío emplazadas en rocas principalmente paleozoicas (Figura 1).

De acuerdo con criterios petrológicos (Gastil, 1983) y geoquímicos (Silver et al., 1979), el Cinturón Batolítico Peninsular (CBP) se ha dividido en las zonas occidental (Symons et al., 2003) y oriental (plutones tipo La Posta), separadas básicamente por la línea magnetita-ilmenita definida con base en mediciones aeromagnéticas por Gastil

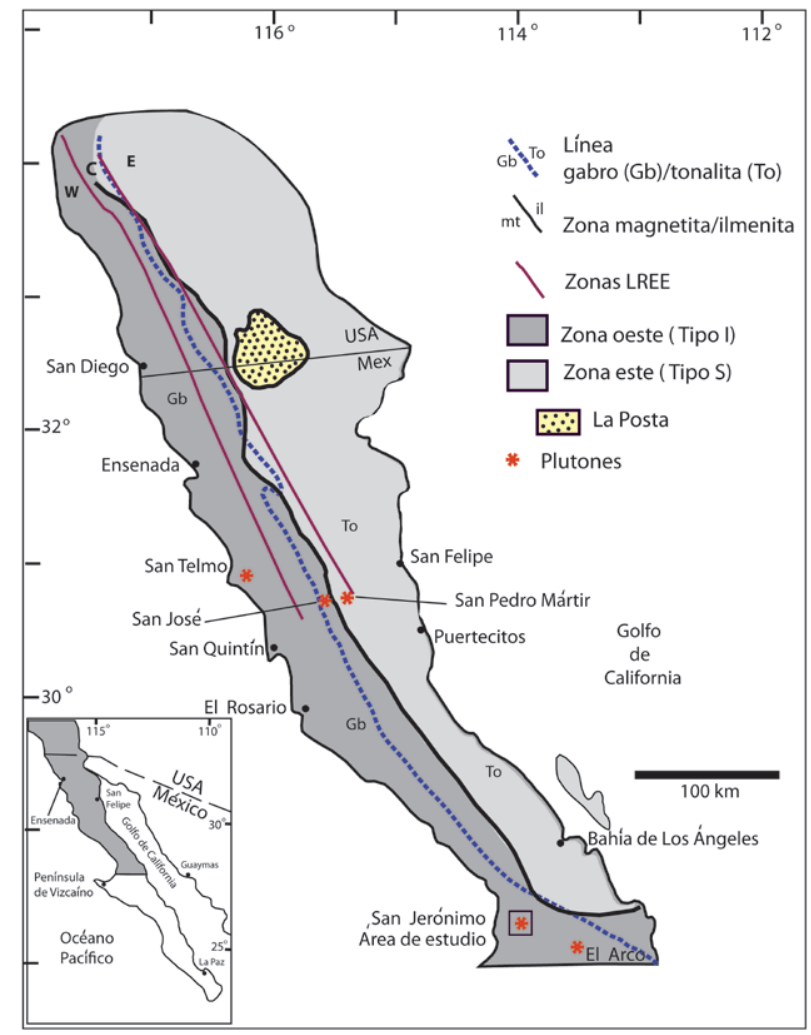

Figura 1. Mapa del Cinturón Batolítico Peninsular (CBP), mostrando la zona magnetita-ilmenita (Gastil et al., 1990), la separación por zonas oeste (W), central (C) y este (E) según el incremento en la proporción de tierras raras ligeras (LREE) de occidente a oriente a través del CBP, según Gromet y Silver (1987) y la línea gabro-tonalita (Gb-To; Gastil, 1983). Los asteriscos muestran la localización de cuatro de los complejos plutónicos mejor estudiados, así como el de este estudio, San Jerónimo (modificada de Schmidt et al., 2002). et al. (1990), la cual guarda cierto paralelismo con la línea gabro-tonalita (Gastil, 1983) de la Figura 1.

Geológicamente, los plutones de la zona occidental se caracterizan por tener afinidad con un ambiente de arco de islas, por lo que están encajonados por secuencias volcánicas, volcanosedimentarias y sedimentarias de varios tipos, metamorfoseadas comúnmente a facies de esquistos verdes y anfibolitas (Gastil et al., 1975). Las rocas plutónicas de esta zona pertenecen a la serie de la magnetita, cuyas susceptibilidades magnéticas son del orden de $130 \times 10^{-5}$ SI Son generalmente rocas metaluminosas (granitos tipo I) con rangos de edad entre 140 y $105 \mathrm{Ma}$ (Silver et al., 1979; Gastil et al., 1990). Composicionalmente varían principalmente entre gabro y tonalita, con un contenido moderado de $\mathrm{K}_{2} \mathrm{O}$. En el sur del CBP los complejos plutónicos occidentales son de tipo anidado y notablemente más pequeños que los de la zona oriental (Delgado-Argote et al., 2006). Los plutones de la zona oriental tienen afinidad con corteza continental, intrusionan rocas correspondientes al miogeoclinal cordillerano del Paleozoico, son plutones del Cretácico medio (105 Ma y 90 Ma; Silver y Chappell, 1988; Kimbrough et al., 2001). Pertenecen a la serie de la ilmenita, son peraluminosos (granitos tipo $\mathrm{S}$ ) y son rocas muy ricas en $\mathrm{K}_{2} \mathrm{O}$.

Se ha documentado que los batolitos de las dos zonas tienden a mostrar zonación casi concéntrica, observándose que los núcleos en los cuerpos de la región occidental (ricos en magnetita) son máficos, mientras que los de la región oriental (ricos en ilmenita) son félsicos (Gastil et al., 1975). Trabajos a detalle en plutones con núcleos gabróicos y dioríticos (Delgado-Argote et al., 1995) muestran que las rocas más máficas son las más antiguas y que las más jóvenes son principalmente monzoníticas y están en la periferia.

De manera general, se interpreta que el CBP representa las raíces plutónicas de un extenso sistema de arco. Gastil et al. (1975) consideran que en el norte de Baja California dicho CBP está constituido por más de 400 plutones discretos, que a su vez varían en sus dimensiones; la mayoría de ellos muestran una estructura de exposición circular, por lo que los últimos autores suponen que los cuerpos son diapiros, independientemente de su composición, y que la variedad en el diámetro depende del nivel de exposición (Gastil et al., 1975).

El área de estudio se localiza en el extremo sudoeste del CBP, entre las coordenadas geográficas $28^{\circ} 16^{\prime}$ y $28^{\circ} 23^{\prime}$ de latitud norte y $113^{\circ} 55^{\prime}$ y $113^{\circ} 50^{\prime}$ de longitud oeste (Figura 2); forma parte del batolito de San Jerónimo, el cual cubre $200 \mathrm{~km}^{2}$ aproximadamente. La parte norte del batolito es muy homogénea litológicamente, mientras que la parte sur tiene características litológicas y estructurales más variadas, razón por la que se ha elegido la parte sur para realizar este estudio. La zona comprende aproximadamente $113 \mathrm{~km}^{2} \mathrm{y}$, en este estudio, se le denomina plutón San Jerónimo (PSJ).

En este trabajo se correlacionan los patrones de fracturas primarias de las rocas intrusivas con la dirección de flujo del 


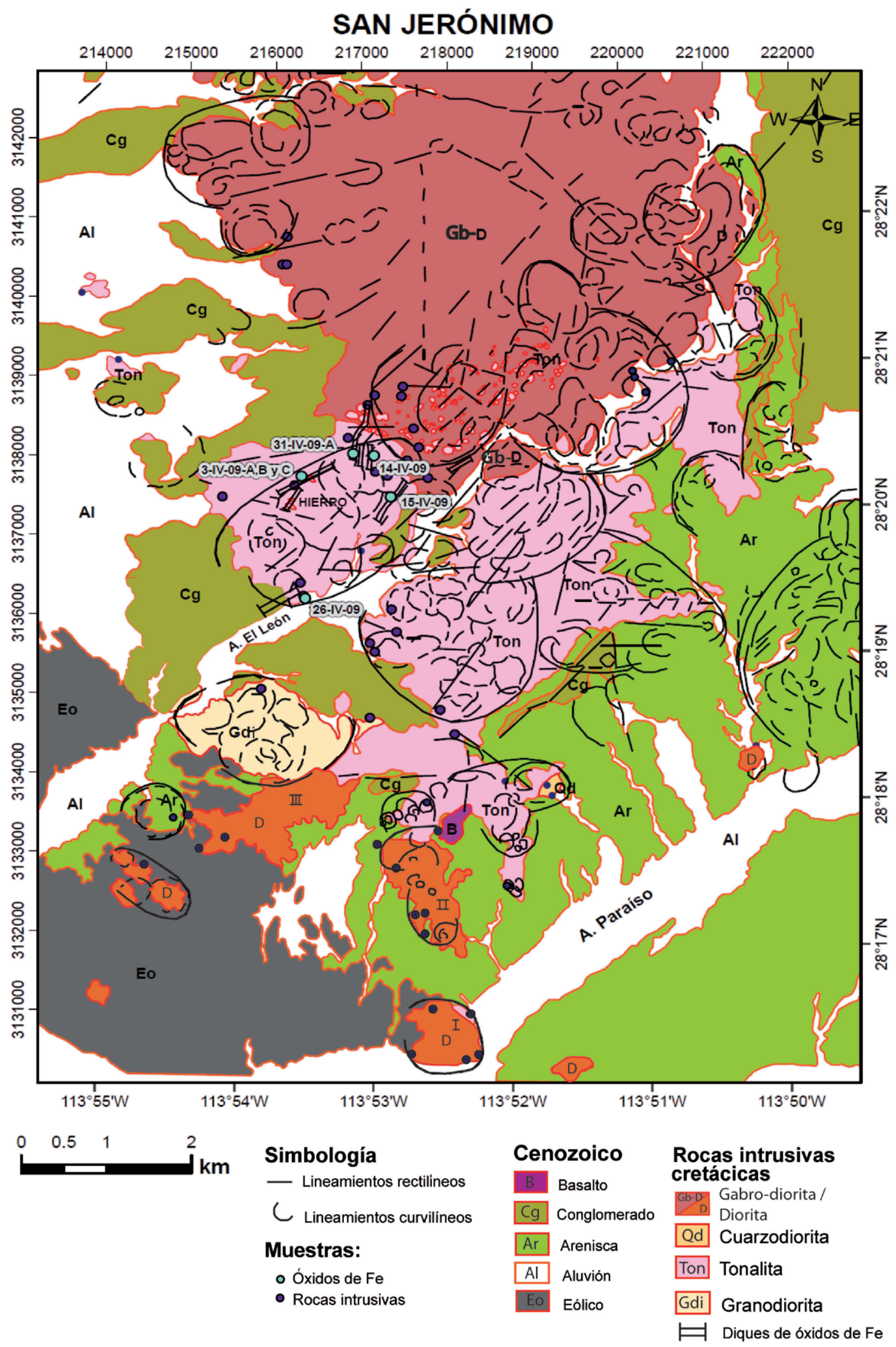

Figura 2. Mapa geológico del plutón San Jerónimo (PSJ) donde se indican los rasgos estructurales rectilíneos y curvilíneos más importantes interpretados en base a imágenes de satélite. Los números con fondo azul indican las muestras de diques de óxidos de fierro analizadas. Los números (I, II y III) representan cuerpos de diorita del sur. 
magma, así como la susceptibilidad magnética y la respuesta aeromagnética con la composición de las rocas plutónicas, principalmente entre diorita y tonalita y menas de óxidos de Fe aflorantes en forma de diques, cuyo origen es magmático. Estos diques tienen concentraciones aproximadas de hasta $90 \%$ de óxidos de Fe.

Finalmente, se propone un mecanismo de emplazamiento de las rocas intrusivas y de los diques de Fe, así como la posible extensión a profundidad de éstos últimos a partir del modelado bidimensional de perfiles aeromagnéticos.

\section{Geología local}

A partir de la cartografía geológica de campo y del contenido mineralógico y rasgos texturales identificados del análisis petrográfico de muestras características, se identificaron cinco unidades litológicas básicas en el PSJ (Figura 3): 1) Gabro de 2Px, Diorita de Hbl-Cpx y Diorita de Cpx-Hbl-Bi; 2) Cuarzodiorita; 3) Tonalita y diques aplíticos de la misma composición; 4) Granodiorita; y 5) diques de óxidos de Fe. Dos muestras de diques félsicos fueron clasificadas como granito (Torres-Carrillo, 2010).

\subsection{Diorita y gabro}

La diorita y el gabro son los tipos de roca dominante en la parte norte del PSJ. Dichos tipos de roca, cuyo aspecto en el campo es similar, se clasificaron a partir del análisis petrográfico, por lo que de acuerdo con la cartografía geológica, ambas se agrupan en una sola unidad intrusiva denominada gabro-diorita. El cuerpo máfico gabro-diorítico del norte es muy homogéneo, de grano grueso y con susceptibilidad magnética alta a muy alta $\left(13.8 \times 10^{-3} \mathrm{SI}\right.$ a $\left.156 \times 10^{-3} \mathrm{SI}\right)$. Según el análisis modal, los minerales constituyentes son, en orden de abundancia: plagioclasa $60-70 \%$, clinopiroxeno 15.5 - $23 \%$, hornblenda hasta $13 \%$ y opacos 1 - $5 \%$. Es frecuente que los cristales de plagioclasa estén alineados marcando la dirección de flujo.

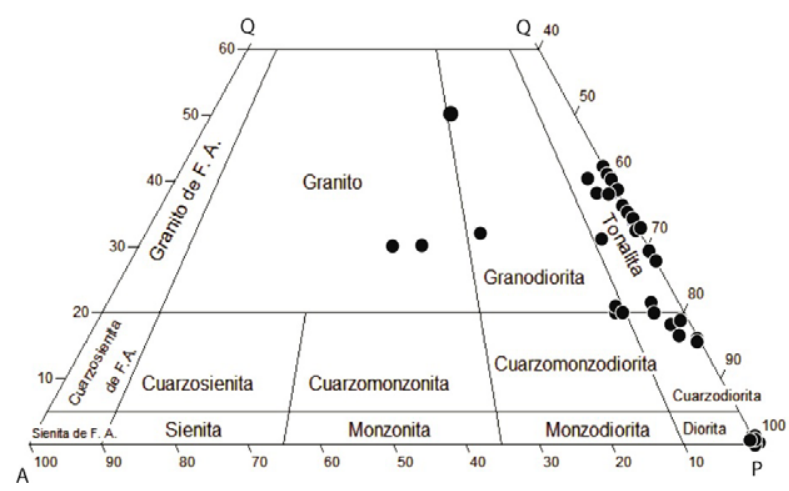

Figura 3. Diagrama QAP para rocas plutónicas (LeMaitre, 2002), que muestra la clasificación modal de las muestras colectadas en el PSJ. Los granitos corresponden a diques.
En estas rocas es también frecuente encontrar enclaves afaníticos de composición diorítica elongados con dirección dominante NE - SW, subparalelos a la foliación magmática. La parte sur de este cuerpo máfico está cortado por diques de composición tonalítica orientados $\mathrm{E}-\mathrm{W}$, cuyos espesores pueden alcanzar hasta $30 \mathrm{~m}$. En esta zona también se puede observar una zona de mezcla formada por enclaves de diorita embebidos en tonalita, lo que muestra que la roca félsica es posterior a la máfica (Figura 4A). En los bordes NW y NE de esta misma masa máfica existen zonas de cizalla con orientación NE - SW.

En la zona sur del área de estudio se identifican tres cuerpos intrusivos cercanos a $1 \mathrm{~km}^{2}$ de composición principalmente diorítica (I, II, y III; Figura 2). Una característica mineralógica que los hace distintos de otros intrusivos dioríticos, tanto en la zona de estudio como regionalmente (Delgado-Argote et al., 2009), es la presencia de biotita. El cuerpo diorítico I sobre el arroyo Paraíso,

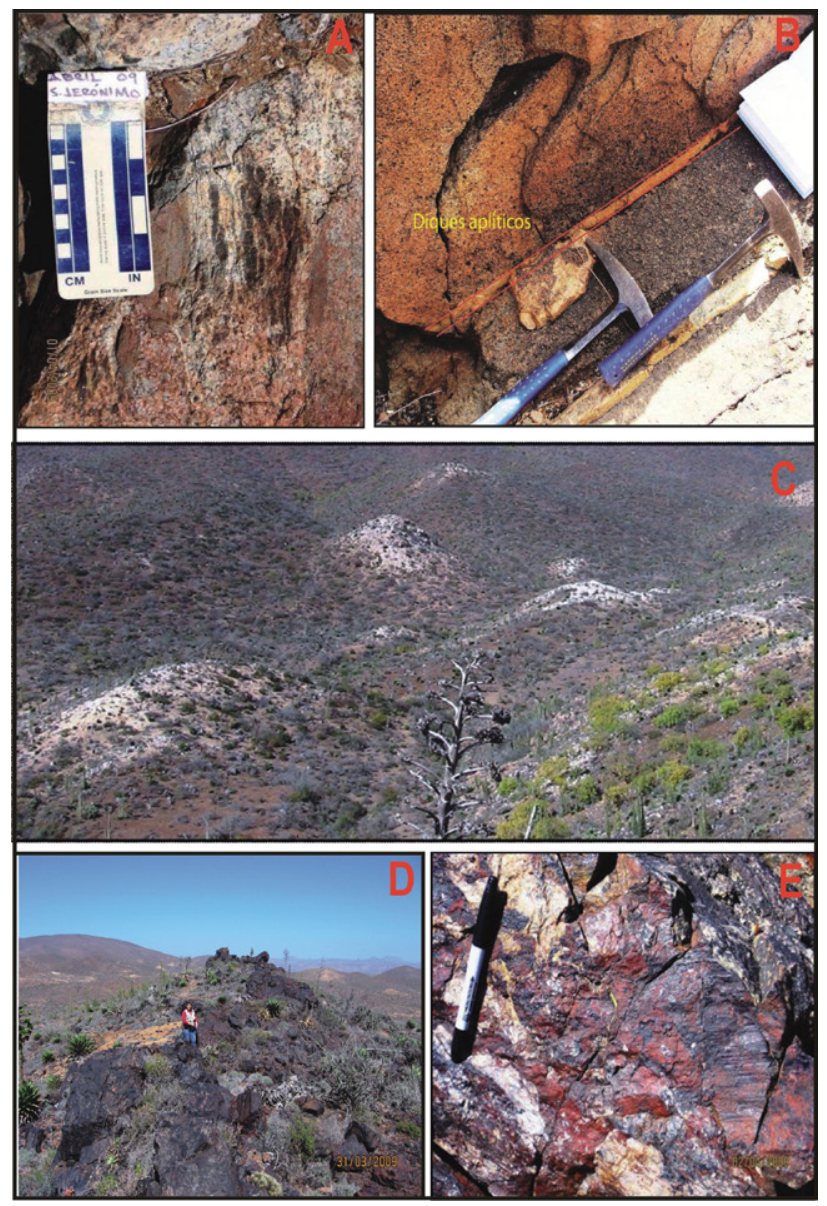

Figura 4. A) Zona de mezcla entre magma diorítico y tonalítico. Se observan enclaves de diorita máfica de grano fino en la tonalita félsica. B) Diques aplíticos de tonalita emplazados en fracturas verticales y horizontales de diorita, indicados con la posición de los martillos. C) Vista panorámica de los plugs tonalíticos que intrusionan a la diorita de la zona norte. D) Dique de óxidos de Fe con vetillas de sílice orientadas en la dirección del flujo. E) Plano de cizalla en el mismo dique de óxidos de Fe. 
tiene una susceptibilidad magnética que varía entre $20.5 \mathrm{x}$ $10^{-3} \mathrm{SI}$ y $5.30 \times 10^{-3} \mathrm{SI}$, contiene enclaves subredondeados más máficos, es marcadamente isotrópico y tiene fracturas notablemente ortogonales donde se forman diques aplíticos de aproximadamente $3 \mathrm{~cm}$ de espesor (Figura 4B). El análisis modal de las muestras de diorita muestra la siguiente distribución: 62 a $78 \%$ de plagioclasa, 4 a $17 \%$ de hornblenda, hasta $5 \%$ de biotita, 2 a $10 \%$ de clinopiroxeno $\mathrm{y}$ trazas de minerales opacos.

En el cuerpo diorítico II (Figura 2) resalta la presencia de una zona de mezcla entre rocas félsicas y máficas sin rasgos de foliación magmática. Una de las características más sobresalientes de este cuerpo es la presencia de abundantes intrusivos pequeños de diorita félsica de hasta $50 \mathrm{~m}$ de diámetro (plugs); su arreglo es alineado en forma anular y poseen clara foliación magmática. El cuerpo diorítico III muestra una foliación bien desarrollada. Localmente, al igual que en el cuerpo II, en esta diorita los plugs de diorita félsica de hasta $30 \mathrm{~m}$ de diámetro son comunes. Otros cuerpos de diorita máfica, menores y aislados, magnéticos y sin biotita aparente, afloran en el extremo occidental de la zona de los intrusivos dioríticos I, II y III.

\subsection{Tonalita}

La tonalita, que aflora en la parte central del plutón San Jerónimo y está disectada por el arroyo El León, se caracteriza por alojar diques de óxidos de fierro. Estas rocas félsicas son principalmente de grano medio, su susceptibilidad magnética es baja a moderada $\left(2.69 \times 10^{-3}\right.$ SI a $55 \times 10^{-3} \mathrm{SI}$ ) y es homogénea mineralógicamente. El análisis modal arroja los siguientes resultados: plagioclasa 47 a $63 \%$, hornblenda hasta $11 \%$, biotita de 2 a $15 \%$, clinopiroxeno hasta $8 \%$, trazas de zircón y apatita, y opacos, principalmente magnetita, están diseminados en la mayoría de la muestras.

Algunos cuerpos tonalíticos que intrusionan la parte sur de la unidad gabro-diorítica del norte son circulares en planta, tienen diámetros que oscilan entre 15 y $30 \mathrm{~m}$, su susceptibilidad magnética es muy baja $\left(0.0217 \times 10^{-3} \mathrm{SI}\right.$ a $0.417 \times 10^{-3} \mathrm{SI}$ ) y se interpreta que tienen una geometría similar a la de los plugs (cuellos o pitones volcánicos; Figura 4C).

La unidad tonalítica en su zona centro-noroeste está cortada por diques compuestos por óxidos de fierro que sobresalen como crestas orientadas preferentemente en dirección NE-SW. En los contactos con diques de Fe la tonalita tiene comúnmente una textura aplítica, lo que indica que su cristalización puede asociarse con ambientes de baja presión, rápido enfriamiento y alta nucleación (Hibbard, 1995). Se observa que la presencia de rocas con texturas aplíticas y porfídicas está relacionada con la presencia de diques de óxidos de fierro; Las texturas aplíticas son más comunes en los diques tonalíticos que cortan la parte sur del cuerpo gabro-diorítico.

Los intrusivos tonalíticos al sur del arroyo El León también tienen aspecto félsico, con valores de susceptibilidad magnética más bajos que los de las rocas máficas $(26.4 \mathrm{x}$ $10^{-3} \mathrm{SI}$ a $0.0115 \times 10^{-3} \mathrm{SI}$ ); texturalmente varían de grano fino a grueso. La foliación magmática de la tonalita de esta zona tiene una orientación principal E - W.

\subsection{Diques de óxido de fierro}

Los diques de óxido de fierro destacan en el paisaje por su resistencia a la erosión. Tienen espesores expuestos entre 5 y $10 \mathrm{~m}$ y como se menciona anteriormente están emplazados en la tonalita de la parte centro-noroeste del plutón (Figura 4D). Mineralógicamente son muy homogéneos, notándose en sitios determinados un aumento en los silicatos, principalmente cuarzo y piroxenos, los cuales, en conjunto, no superan el $5 \%$. Una selección de siete muestras características de los diques de óxido de fierro muestra que están compuestos principalmente por magnetita, con cantidades subordinadas de cuarzo $>$ opx $>\mathrm{cpx}>$ apatita. Las propiedades físicas de estos diques no son homogéneas, pues la susceptibilidad magnética a escala de centímetros puede variar en los cuerpos de fierro; es evidente que cuando los silicatos están ausentes la susceptibilidad magnética es mayor. Los diques tienden a orientarse paralelamente al sentido dominante de las fracturas verticales de la tonalita, cuya orientación es $227^{\circ}$ $/ 88^{\circ}$

Durante el análisis petrográfico y de microscopía electrónica de barrido de las muestras de los diques 3-IV09A, 3-IV-09-B, 3-IV-09-C, 14-IV-09, 15-IV-09, 26-IV09 y 31-IV-09B (Figura 2), se observaron abundantes cristales de ortopiroxeno hasta de $2 \mathrm{~mm}$. Algunos de estos cristales tienen fracturas rellenas de magnetita y algunos son oikocristales con inclusiones de anfíbol. También se observó en todas las láminas un alto contenido de apatita, generalmente incluida en los piroxenos. En algunos casos los minerales opacos tienen formas euedrales características de la magnetita pero, en general, son anedrales. Con luz reflejada destacan las texturas de aspecto botroidal (Figura $5 \mathrm{~A})$, las cuales se desarrollan en espacios abiertos donde circulan soluciones hidrotermales (Hibbard, 1995).

El análisis de muestras de los diques de óxidos de fierro con el microscopio electrónico de barrido muestra que, en su mayoría, los minerales opacos están compuestos por óxidos $\mathrm{Fe}$ y que la presencia de Ti es prácticamente nula, pues sólo se observó en la lámina (3-IV-09B; Figura 5B) como exsolución sólida. A partir de los barridos realizados en zonas seleccionadas de las láminas se observó que los elementos más abundantes en estos diques, son: $\mathrm{Fe}, \mathrm{Mg}$, $\mathrm{Si}, \mathrm{Al}$ y Na (Figura 6). Los silicatos en estas muestras son tabulares subedrales de tamaño entre 0.3 y $1 \mathrm{~mm}$, mientras que la sílice aparece rellenando espacios (Figura 5C). 

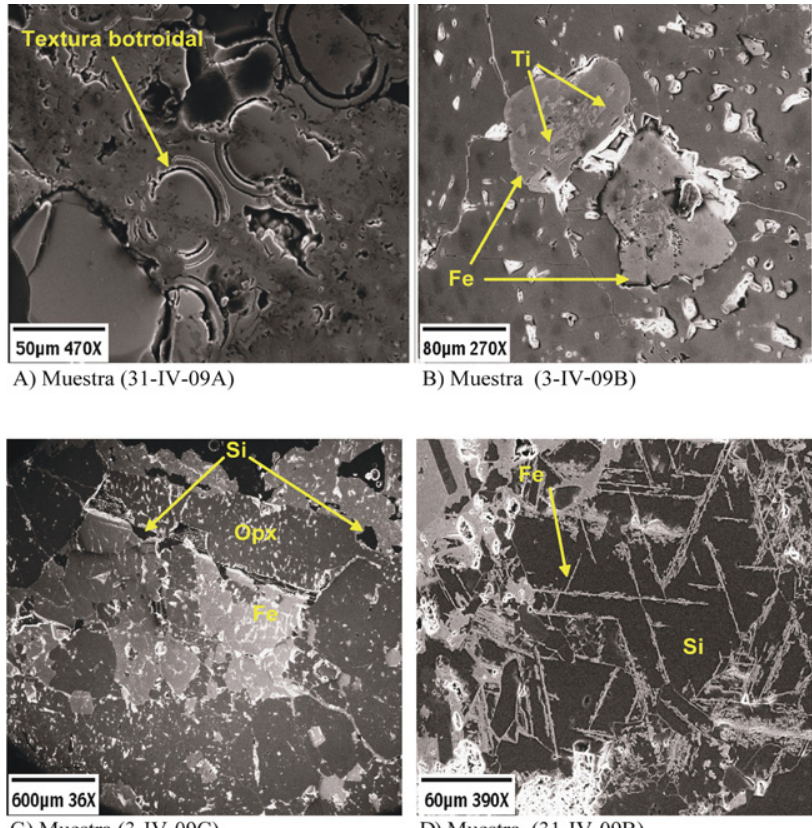

C) Muestra (3-IV-09C)

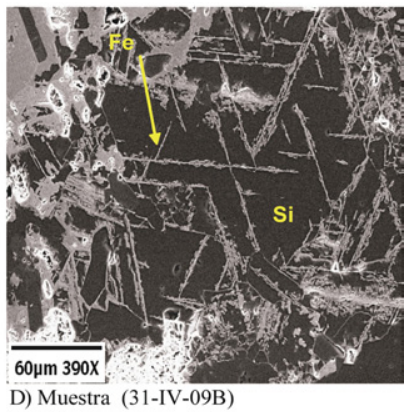

Figura 5. A) Imagen del microscopio electrónico de barrido donde se observa textura botrioidal. B) Cristales de magnetita (Fe) con exsoluciones de Ti. C) Ortopiroxenos tabulares en contacto con óxidos de Fe y sílice. D) Sílice con textura en enrejado de vetillas de Fe.

\section{Geología estructural}

Al interpretar rasgos estructurales lineales y curvilíneos a partir de imágenes de satélite se generó el mapa de la Figura 2, donde se muestran los lineamientos rectilíneos más importantes, cuyas longitudes varían de 0.5 a 1.5 $\mathrm{km}$, aunque pueden alcanzar los $6 \mathrm{~km}$. La orientación dominante es NE - SW, paralela al arroyo El León el cual atraviesa al plutón a lo largo del contacto entre diorita y tonalita, principalmente. La dirección de otros grupos lineales importantes es NNE, mientras que otros rasgos con longitudes mayores a $2 \mathrm{~km}$ se orientan ENE y WNW; prácticamente todos cortan a las rocas gabro-dioríticas del norte. En la unidad tonalítica al sur del arroyo El León se observa que el sistema lineal predominante es NE-SW coincidente con la alineación de diques y otros intrusivos menores.

Los rasgos curvilíneos reflejan la dinámica del magma, así como la geometría resultante de su emplazamiento y exhumación. En el mapa interpretativo de la Figura 2, se pueden identificar por lo menos quince cuerpos con formas circulares y elípticas que pueden representar pulsos principales de intrusión magmática. Estos pulsos, que se manifiestan como troncos, tienen dimensiones que varían entre 3 y $6 \mathrm{~km}^{2}$, los cuales, a su vez, están formados por otras intrusiones circulares cuyas dimensiones varían entre 70 y $800 \mathrm{~m}^{2}$. El arreglo geométrico resultante del conjunto de intrusivos discretos le imprime un aspecto anidado al plutón en su conjunto. Es importante notar que los troncos, que pueden asociarse a pulsos verticales, tienden a orientarse

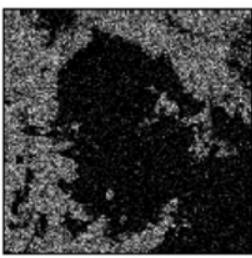

(AI)

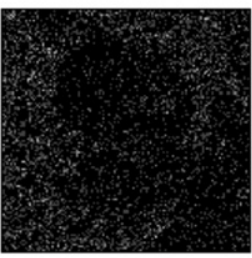

(Na)

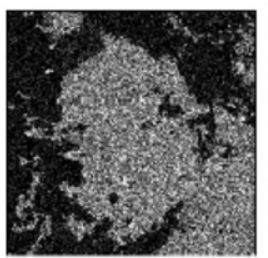

(Fe)

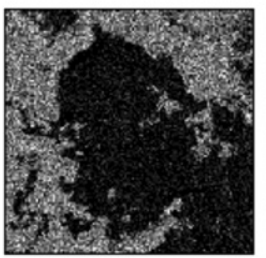

(Si)

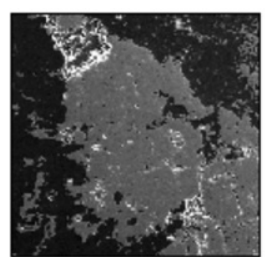

Mapa

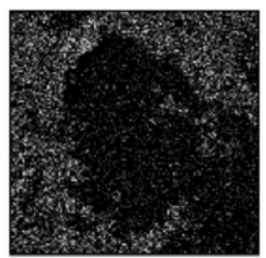

(Mg)

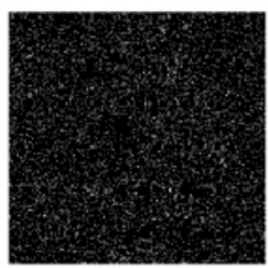

(Ti)
Figura 6. Imágenes de barridos por elementos, tomados de la lámina 26IV-09 del intrusivo. Los elementos detectados se ven de color blanco. Se observa que el mineral opaco en el mapa está compuesto por Fe y rodeado por un silicato rico en $\mathrm{Al}$ (Plag) y $\mathrm{Mg}(\mathrm{Px})$.

en la dirección principal de los rasgos rectilíneos NE - SW. Las estructuras curvilíneas sobre sedimentos pueden indicar la presencia de rocas cristalinas pertenecientes al plutón por debajo de dicha cubierta.

\subsection{Análisis de fracturas}

Los plutones tienen formas regulares y estructuras bien definidas que generalmente se reflejan en sus sistemas de fracturas primarias. De acuerdo con Price y Cosgrove (1991), el desarrollo de fracturas en las rocas intrusivas se favorece en niveles intermedios y altos de la corteza al disminuir la presión confinante. Las fracturas que se desarrollan en las márgenes de las cámaras magmáticas son importantes pues reflejan la historia térmica del plutón en formación. Al cristalizar el magma a partir del contacto con las rocas encajonantes, y alcanzar un estado de rigidez (más de $70 \%$ de cristales; Sinton et al., 1992; Marsh, 2000), su comportamiento es frágil y las fracturas primarias desarrolladas en esta etapa tenderán a rellenarse con líquido residual o nuevo líquido del interior del cuerpo parcialmente fundido. Una descripción de los tipos de fracturas características de los plutones de la zona de estudio y las relaciones entre ellas se discute ampliamente en Torres-Carrillo (2010). 


\subsubsection{Fracturas en las rocas plutónicas del complejo San Jerónimo}

En el plutón San Jerónimo se midieron sistemáticamente fracturas primarias, tanto verticales, como horizontales. Las horizontales, que de acuerdo con Phillips (1974; citado en Price y Cosgrove, 1991) tienden a ser paralelas a los esfuerzos principales mínimos, no aportaron información relevante pues son escasas y al graficarlas en la red estereográfica no presentan un patrón definido. En cambio, de acuerdo con los autores citados, las numerosas fracturas verticales son paralelas a la dirección de movimiento del magma y al esfuerzo principal máximo, por lo que pudieron agruparse en las unidades gabro-diorítica y tonalítica (Figura 7). En este mapa se observa que los polos de las fracturas verticales en el cuerpo gabro-diorítico del norte definen planos promedio en dos direcciones casi ortogonales: uno $12^{\circ} / 88^{\circ}$ y otro, perpendicular, orientado $270^{\circ} / 81^{\circ}$ (Figura 7a). Dichos planos de fracturas son casi paralelos a las orientaciones de los lineamientos rectilíneos más importantes del intrusivo gabro-diorítico. Las fracturas de la tonalita muestran una tendencia según el plano promedio $47^{\circ} / 88^{\circ}$ (Figura $7 \mathrm{c}$ ) que es casi igual a la de los diques de

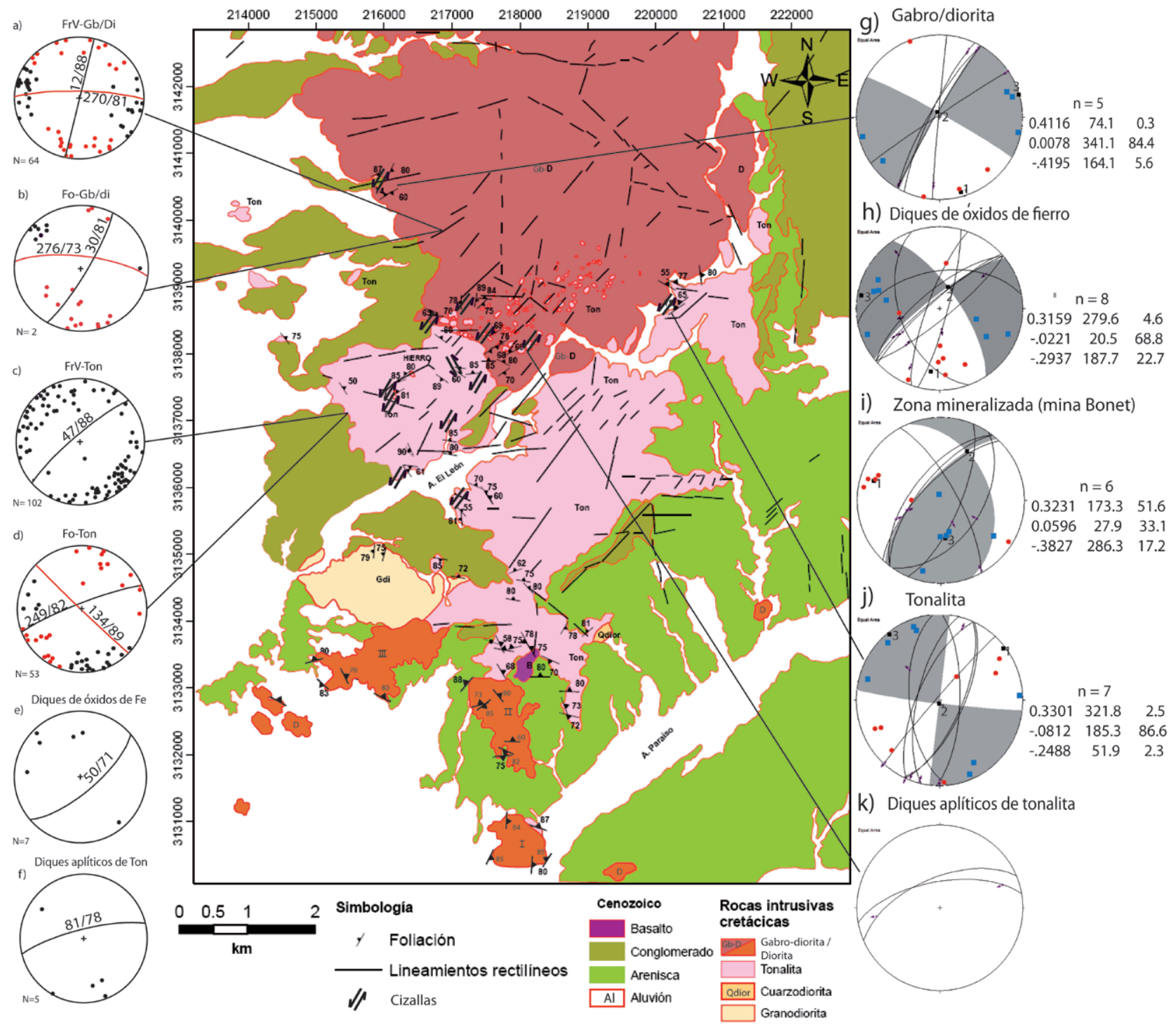

Figura 7. Mapa geológico donde se muestra la foliación magmática, lineamientos y los estereogramas según la proyección de Schmidt, indicando los planos promedio de las foliaciones, fracturas verticales $(a, b, c, d, e, \mathrm{y} f)$, el resultado del análisis cinemático de los planos de cizalla del plutón San Jerónimo $(g, h, i$ y $j)$ y los planos promedio de los diques aplíticos de tonalita $(k)$ En cada gráfica se representan los planos de falla y la lineación de sus estrías. Los números 1, 2 y 3 dentro de las gráficas representan el eje de extensión máxima, el eje intermedio de deformación y el eje de acortamiento máximo, respectivamente. El número de datos o mediciones realizadas está representado por "n". Para cada uno de los gráficos del análisis cinemático la columna de la izquierda representa los eigenvalores y las columnas del centro y derecha representan los eigenvectores (azimut e inclinación, respectivamente). También se representan los ejes $\mathrm{P}$ (círculos rojos) y T (cuadros azules) para cada una de las fallas. Abreviaturas: Fo = Foliación; FrV = Fracturas verticales; $\mathrm{Gb} / \mathrm{di}=$ Gabro diorita; Ton $=$ Tonalita; $\mathrm{Fe}=$ Fierro; $\mathrm{n}=$ Número de datos . 
óxidos de fierro que cortan a este cuerpo y cuya dirección promedio es $50^{\circ} / 71^{\circ}$ (Figura $7 \mathrm{e}$ ).

\subsection{Foliación magmática}

Se midió la foliación magmática a partir del arreglo cristalino de plagioclasas, hornblendas y biotitas, principalmente $\mathrm{y}$, ocasionalmente, la orientación de enclaves elongados. También la foliación en las rocas gabro-dioríticas tiende a ser ortogonal. El primer grupo de datos define un plano promedio orientado $30^{\circ} / 81^{\circ}$ (Figura $7 \mathrm{~b}$ ), correspondiente a las zona periféricas del noroeste del cuerpo gabro-diorítico, mientras que el grupo perpendicular al anterior está definido por el plano promedio $276^{\circ} / 73^{\circ}$, que corresponde a la actitud de la foliación de la parte sur del mismo cuerpo. Se observa que las orientaciones de las foliaciones son similares a las de los planos de fracturas verticales, por lo que se interpreta que los planos de fracturas verticales son de tipo longitudinal, paralelas a la dirección de flujo.

Los patrones de foliación en la tonalita de la zona centro oeste son distintos. En este cuerpo, se observan dos grupos principales de foliación con arreglo ortogonal (Figura 7d); uno se orienta $249^{\circ} / 82^{\circ}$ y es casi paralelo al plano promedio de fracturas verticales en esta roca, mientras que el otro plano de foliación promedia $132^{\circ} / 89^{\circ}$. Por la relación con las fracturas verticales se deduce que la dirección principal de flujo en este magma tonalítico es NE - SW, lo cual coincide con la dirección de los diques aplíticos de composición tonalítica (Figura 7f).

\subsection{Planos por cizalla}

En otro nivel de estructuras, se reconocieron cinco zonas con desarrollo de superficies con estrías que indican deformación en ambiente frágil. Dos de ellas están en los márgenes oriental y occidental del cuerpo gabro-diorítico, y las tres restantes se desarrollan en los diques de Fe.

En la zona de falla del occidente del cuerpo gabrodiorítico se midieron cinco planos de cizalla. El análisis cinemático de estos cinco planos muestra un eje de acortamiento máximo subhorizontal $164^{\circ} / 6^{\circ}$ y un eje de extensión máximo horizontal $74^{\circ} / 0^{\circ}$ que correspondería a una zona de cizalla con movimiento lateral izquierdo (Figura 7g).

En todos los diques de Fe emplazados en la tonalita al norte del arroyo El León se identificaron planos con estrías casi paralelos. Los más notables tienen un rumbo general $50^{\circ}$ y una inclinación predominante hacia el SE con ángulos variables entre $52^{\circ}$ y $83^{\circ}$. El resultado del análisis cinemático muestra un eje de acortamiento máximo orientado $188^{\circ} / 23^{\circ}$ y un eje de extensión máximo casi horizontal, según $280^{\circ}$ $/ 5^{\circ}$. Como se observa en la Figura $7 \mathrm{~h}$, los planos nodales son $326^{\circ} / 71^{\circ}$ y $232^{\circ} / 78^{\circ}$, lo cual indica, como en el caso de la zona de cizalla en el occidente de la diorita, que el movimiento en el plano dominante es izquierdo.
En los diques aplíticos de tonalita sólo se observaron dos planos de cizalla con rumbo promedio $256^{\circ} / 78^{\circ}$. Como se ha mencionado anteriormente, los diques tonalíticos tienen una relación espacial muy estrecha con los diques de fierro, por lo que los planos con estrías asociados a cizallas posiblemente también estén relacionados con el emplazamiento de los diques metálicos (Figura 7k).

En un frente de diques de fierro se midieron seis planos estriados en una cata de exploración minera, y del análisis cinemático de ellos se obtuvo un eje de acortamiento máximo orientado $286^{\circ} / 17^{\circ}$ y un eje de extensión máximo en $173^{\circ} / 52^{\circ}$; los planos nodales se orientan $326^{\circ} / 71^{\circ}$ y $231^{\circ} / 78^{\circ}$ (Figura $7 \mathrm{i}$ ). Dichas orientaciones muestran una dirección del esfuerzo compresivo máximo perpendicular a las tres soluciones anteriores, el cual puede resultar del empuje del cuerpo tonalítico más joven contra la masa diorítica más antigua, provocando rotación en la zona de contacto en el sentido de las manecillas del reloj.

En el extremo oriental del cuerpo gabro-diorítico, en la tonalita cercana al contacto localizado en el arroyo El León, se mapeó una amplia zona de falla lateral izquierda cuyos planos con estrías se observan por más de $100 \mathrm{~m}$ a lo ancho de la zona de falla. El análisis cinemático de esa zona muestra que los ejes compresivo y de extensión máximos se orientan según $52^{\circ} / 2^{\circ}$ y $321^{\circ} / 2^{\circ}$, respectivamente (Figura 7j). La diferencia principal entre las zonas de cizalla asociadas con los diques de fierro y esta última zona de falla que pone en contacto dos unidades litológicas principales, son las dimensiones mayores de la zona de falla, por lo que, como se discute adelante, su naturaleza debe ser distinta.

\section{Magnetometría}

En esta sección se presentan la relación entre óxidos de fierro analizados en el microscopio electrónico y los valores de susceptibilidad magnética de los distintos tipos de roca, y se analiza la distribución de los valores magnéticos a través del plutón. Se mostrará también el mapa magnético del área de estudio, utilizando el levantamiento aereomagnético adquirido del Servicio Geológico Mexicano (SGM, 2003), a partir del cual se identificaron anomalías magnéticas y su correlación con los rasgos geológicos observados y, por último, se presenta el resultado de la interpretación cualitativa y cuantitativa de estas anomalías.

\subsection{Susceptibilidad magnética}

Con base en los contrastes de susceptibilidad magnética de distintos minerales y rocas se puede inferir la geometría a profundidad de cuerpos con propiedades magnéticas distintas, por lo que se analizaron la susceptibilidad magnética de rocas representativas del plutón y la composición mineralógica de los diques de óxidos de Fe. La susceptibilidad magnética es una medida de la facilidad con que un material puede ser magnetizado. Se utiliza en 
el modelado de anomalías magnéticas y es de uso limitado para discriminar distintas unidades litológicas.

En el conjunto litológico intrusivo del área de estudio que comprende desde el gabro hasta el granito se estimó la moda por medio del análisis petrográfico. Se prestó especial atención a la identificación de los minerales opacos porque, en su mayoría, son óxidos de la serie de la titanomagnetita, como lo indica el análisis por microscopía electrónica (Figuras 5 y 6). Al analizarse la susceptibilidad magnética en muestras seleccionadas se observó que sus valores varían dependiendo del tipo de roca, así como de la concentración y tipo de minerales. Se complementó el estudio petrográfico con la medición de la susceptibilidad magnética en las muestras de roca de las cuales, 32 son intrusivas y siete provienen de los diques de óxido de fierro (Tabla 1).

La medición de la susceptibilidad magnética global (bulk susceptibility) se efectuó en el Laboratorio de Paleomagnetismo del Centro de Investigación Científica y de Educación Superior de Ensenada (CICESE), utilizando un susceptibilímetro KLY3 que consiste en un sistema de bobina pick-up conectado a una PC vía una interfase RS232. La sensibilidad del instrumento es de $2 \times 10^{-8} \mathrm{SI}$, en el rango de 3 a $450 \mathrm{~A} / \mathrm{m}$. Se realizó una medición por cada muestra de aproximadamente $12 \mathrm{~cm}^{3}$.

En la Figura 8a se muestran los rangos de los valores de susceptibilidad magnética de las rocas intrusivas y sus promedios. Las rocas de la unidad gabro-diorítica muestran los valores más altos, donde la diorita tiene la susceptibilidad magnética promedio mayor $\left(72.388 \times 10^{-3} \mathrm{SI}\right)$ que la del gabro $\left(62.295 \times 10^{-3} \mathrm{SI}\right)$ y los valores promedio de ambas son mayores que los de la tonalita $\left(17.816 \times 10^{-3} \mathrm{SI}\right)$. A su vez, destaca que las rocas de la unidad gabro-diorítica tienen mayor susceptibilidad que sus equivalentes de los cuerpos intrusivos I, II y III (Figura 2). Petrográficamente, dicha diferencia se puede explicar al observar que la unidad de gabro-diorita tiene mayor contenido de minerales ferromagnesianos, así como de la serie de la titanomagnetita (Figura 8b), que las rocas dioríticas I, II y III. Al graficar la susceptibilidad magnética contra el porcentaje de magnetita en peso (a partir de la moda recalculada con respecto a la densidad de sus componentes, asignando a la magnetita una densidad de $5.2 \mathrm{gr} / \mathrm{cm}^{3}$; Figura 9a), se observa una buena correlación cuya tendencia, al ajustar una línea por mínimos cuadrados, es lineal.

En vista de que los diques de fierro están encajonados por cuerpos de aspecto tabular de tonalita con textura aplítica, se midió la susceptibilidad magnética de cinco muestras de tonalita y siete de los diques de óxidos de fierro (Tabla 1 y Figura 9b). En la Figura 9b se observa una marcada diferencia entre los valores de susceptibilidad magnética de los diques de óxidos fierro y los tonalíticos. Debe notarse, sin embargo, que existen muestras de diques de óxidos de fierro que tienen susceptibilidades magnéticas muy bajas $\left(<60 \times 10^{-3} \mathrm{SI}\right)$.

Los diques de tonalita tienen una susceptibilidad magnética muy baja debido a que el contenido de minerales
Tabla 1. Se muestran los resultados de susceptibilidad magnética medidas en las muestras del PSJ. Se indican la zona y el numero de muestra a la que pertenecen las rocas, y el contenido en peso (M. Wt \%) de magnetita en los valores de susceptibilidad magnética $\left(\times 10^{-3} \mathrm{SI}\right)$. Abreviaturas: $\operatorname{tr}=$ trazas $<0.1 \%$, n.c. $=$ no hay conteo.

\begin{tabular}{|c|c|c|c|c|c|}
\hline Zona & Muestra & Tipo de Roca & $\begin{array}{l}\text { Coordenadas en UTM } \\
\text { (Este, Norte) }\end{array}$ & $\begin{array}{l}\text { Magnetita } \\
\text { M. Wt \% }\end{array}$ & $\begin{array}{c}\text { Susceptibilidad } \\
\text { Magnética } \\
\left(\times 10^{-3} \mathrm{SI}\right)\end{array}$ \\
\hline Norte & $35-I V-09$ & Diorita & 217525,3138537 & 8.6 & 156 \\
\hline Norte & 26-IV-09 & Dique de $\mathrm{Fe}$ & 216339,3136184 & n.c. & 143 \\
\hline Norte & 33-IV-09 & Gabro 2px & 217525,3138537 & 5.5 & 84.5 \\
\hline Norte & 12-IV-09 & Gabro 2px & 217837,3137505 & 3.4 & 66.3 \\
\hline Norte & 18-VI-09 & Diorita & 220343,3138493 & 5.5 & 66.3 \\
\hline Norte & 7-IV-09 & Gabro 2px & 217592,3137726 & 5 & 60.1 \\
\hline Norte & 31-IV-09B & Dique de $\mathrm{Fe}$ & 216900,3138011 & n.c. & 58.6 \\
\hline Norte & 13-IV-09 & Tonalita & 217220,3137583 & 11 & 55 \\
\hline Norte & 3-IV-09B & Dique de $\mathrm{Fe}$ & 216367,3137511 & n.c. & 53.8 \\
\hline Norte & 22-IV-09 & Diorita & 216181,3140200 & 5.27 & 52.1 \\
\hline Norte & 3-IV-09A & Dique de $\mathrm{Fe}$ & 216367,3137511 & n.c. & 51.7 \\
\hline Norte & 24-IV-09B & Diorita & 215424,3137271 & 3.7 & 43.9 \\
\hline Norte & 32-IV-09 & Tonalita & 217131,3138425 & 3.7 & 33 \\
\hline Norte & 23-IV-09 & Gabro 2px & 216187,3140547 & 1.8 & 20.1 \\
\hline Norte & 20-IV-09 & Diorita & 216069,3140194 & n.c & 13.8 \\
\hline Norte & 31-IV-09 & Tonalita & 216900,3138011 & 2.9 & 13.4 \\
\hline Norte & 14-IV-09 & Dique de $\mathrm{Fe}$ & 217195,3137771 & n.c. & 6.87 \\
\hline Norte & 3-IV-09C & Dique de Fe & 216367,3137511 & n.c. & 5.74 \\
\hline Norte & 5-IV-09 & Tonalita & 216277,3137304 & 8.8 & 3.53 \\
\hline Norte & 6-IV-09 & Tonalita & 217363,3137532 & 1.1 & 2.69 \\
\hline Norte & 4-IV-09 & Diques de Ton & 216273,3137412 & $\operatorname{tr}$ & 0.417 \\
\hline Norte & 10-IV-09 & Diques de Ton & 217670,3138130 & $\operatorname{tr}$ & 0.264 \\
\hline Norte & 9-IV-09 & Diques de Ton & 217670,3138130 & 1.9 & 0.126 \\
\hline Norte & 11-IV-09 & Diques de Ton & 217913,3137839 & 0.1 & 0.117 \\
\hline Norte & 25-IV-09 & Tonalita & 216375,3136022 & 0.2 & 0.0929 \\
\hline Norte & 8-IV-09 & Diques de Ton & 217730,3137890 & 0.1 & 0.0217 \\
\hline Sur & 15-VI-09 & Tonalita & 215453,3132970 & 3.7 & 26.4 \\
\hline Sur & 30-IV-09 & Tonalita & 218152,3134274 & n.c & 26.3 \\
\hline Sur & $1-\mathrm{VI}-09$ & Diorita & 217894,3130800 & 5.4 & 20.4 \\
\hline Sur & 19-IV-09 & Tonalita & 217982,3134579 & 3.7 & 13.4 \\
\hline Sur & 9-VI-09 & Tonalita & 217245,3132884 & 1.9 & 13.3 \\
\hline Sur & 4-VI-09 & Tonalita & 218769,3132360 & 1.9 & 10.7 \\
\hline Sur & $6-\mathrm{VI}-09$ & Tonalita & 217804,3131755 & 1.8 & 8.86 \\
\hline Sur & 13-VI-09 & Diorita & 217825,3133412 & 2.2 & 5.3 \\
\hline Sur & 18-IV-09 & Tonalita & 217156,3135420 & $\operatorname{tr}$ & 3.07 \\
\hline Sur & 5 -VI-09 & Diorita & 217804,3131755 & n.c. & 1.66 \\
\hline Sur & 7-VI-09 & Diorita & 217804,3132015 & 1 & 1.13 \\
\hline Sur & 17-IV-09A & Tonalita & 217470,3135562 & 1.6 & 0.278 \\
\hline Sur & 17-IV-09B & Tonalita & 217470,3135562 & 0.9 & 0.0115 \\
\hline
\end{tabular}

ferromagnesianos y opacos también lo es, razón por la que es muy probable que el contraste entre las susceptibilidades magnéticas entre esas rocas provoque que las anomalías dipolares generadas por los diques de oxido de fierro sean grandes y se puedan detectar fácilmente.

\subsection{Datos aeromagnéticos}

Tomando en consideración los valores de susceptibilidad magnética contrastantes entre las diferentes unidades litológicas del área de estudio, se utilizaron los datos aeromagnéticos de las cartas H11-12, escala 1:250000 del Servicio Geológico Mexicano (SGM, 2003) a fin de identificar diferencias útiles para apoyar la cartografía, así como la existencia de cuerpos magnéticos sepultados. Los valores de intensidad del campo magnético reportados por 


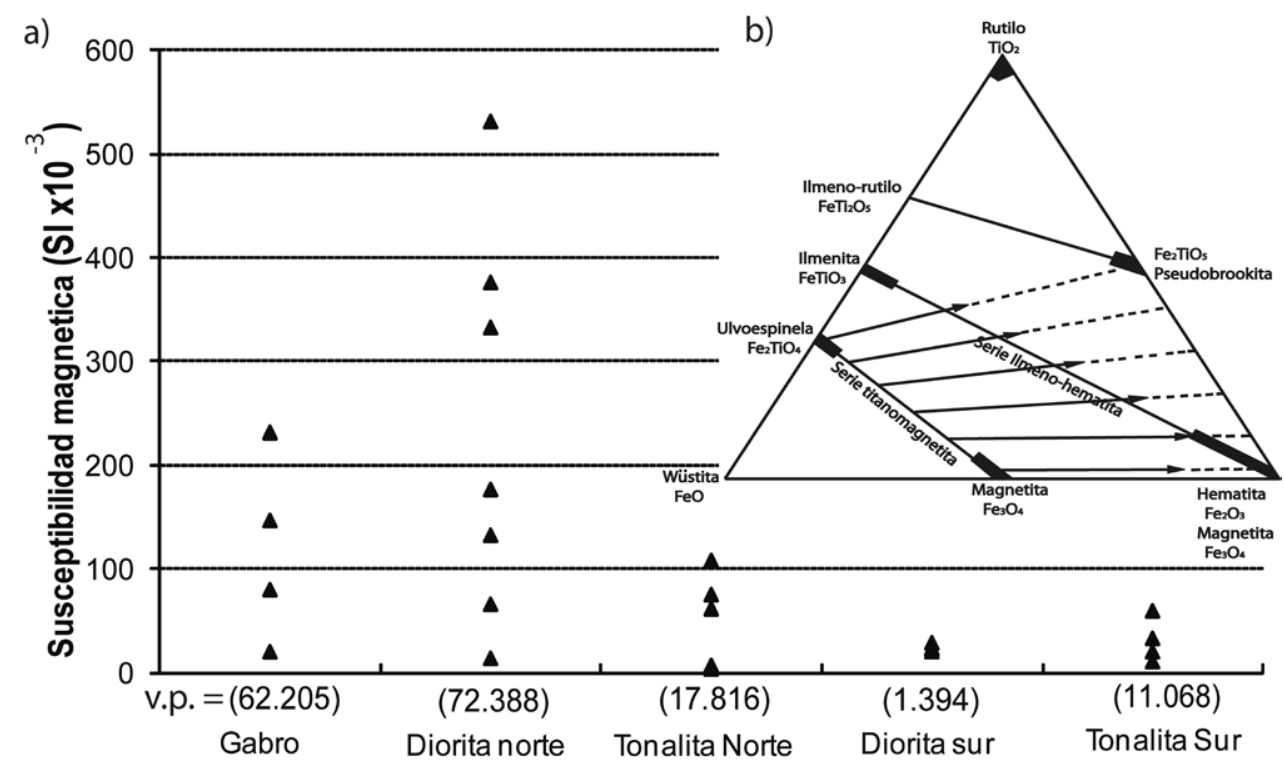

Tipo de Roca

Figura 8. a) Susceptibilidad magnética (x 10-3 SI) de los distintos tipos de roca de la zona norte y sur del área de estudio. El número de muestras graficadas por tipo de roca es el siguiente: gabro 4, diorita norte 7, tonalita norte 6, diorita sur 4, tonalita sur 4. b) Diagrama ternario de la composición de óxidos comunes de Fe-Ti, mostrando las principales series de solución sólida (líneas gruesas). La tendencia en la dirección de oxidación con radio constante Fe/ Ti está indicada con las flechas (Tarling, 1967; en Sharma, 1976). Abreviatura: v.p. = valor promedio.

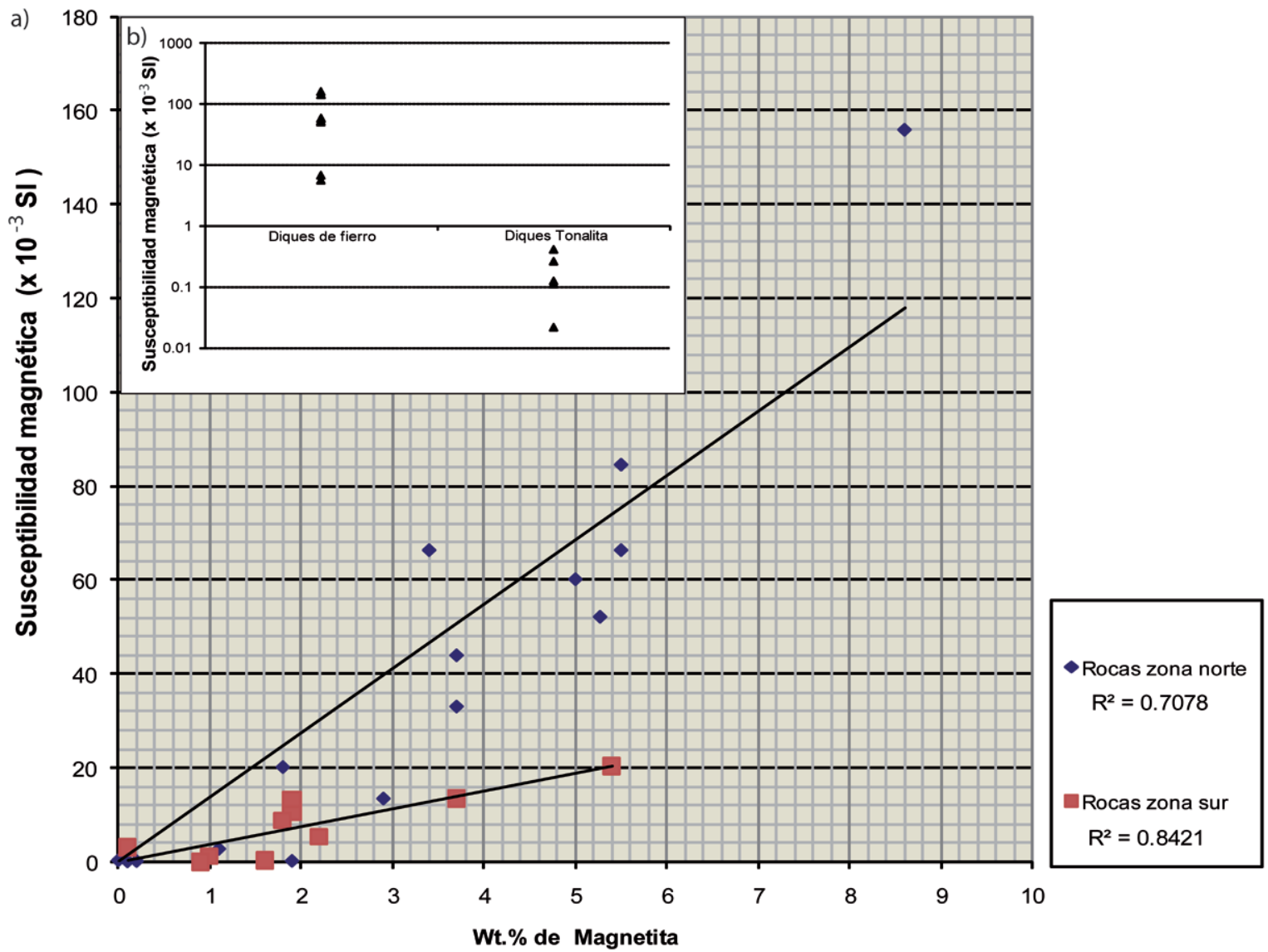

Figura 9. a) Gráfica de los valores de susceptibilidad magnética (x10-3 SI) contra el porcentaje del contenido en peso recalculado a partir del porcentaje de magnetita modal en las rocas. b) Gráfica comparativa de los valores de susceptibilidad magnética (x10-3 $\mathrm{SI})$ de los diques de óxidos de fierro y los diques tonalíticos. Las muestras de diques de fierro son 7 y de las diques de tonalita son 5. 
el SGM fueron adquiridos en líneas orientadas $\mathrm{N}$ - S con una distancia entre líneas de vuelo de $1000 \mathrm{~m}$, con registro cada $250 \mathrm{~m}$, a una altura de vuelo promedio de $300 \mathrm{~m}$. El equipo utilizado fue un par de magnetómetros marca Geometrics G-822A y SCINTREX CS-2, ambos con una sensibilidad de $0.001 \mathrm{nT}$.

Los datos se procesaron en el programa Surfer 8, en donde se separaron los pertenecientes al área de estudio de aproximadamente $120 \mathrm{~km}^{2}$ y se generó una malla regular con separación de $1000 \mathrm{~m}$ con el método de interpolación de mínima curvatura. Para suprimir el efecto regional y resaltar las anomalías producidas por cuerpos pequeños, como los diques de fierro, a esta malla se le aplicó un filtro pasa altas de $3 \times 3$ puntos y se realizó la configuración aeromagnética con contornos de intensidad separados cada $100 \mathrm{nT}$.

El mapa aeromagnético residual resultante se sobrepuso al geológico (Figura 10) y se realizó una interpretación cualitativa basada en el examen de la forma y la intensidad de las anomalías. Se observa en el mapa geológico-magnético que los principales dipolos están en la unidad gabro-diorítica del norte. Sobre esa unidad, el dipolo principal tiene una amplitud de $1300 \mathrm{nT}$ y la parte positiva del dipolo coincide con el afloramiento de un dique de óxidos de fierro. Otro dipolo notable en la región centro-oriental del mapa, sobre el cuerpo de areniscas, tiene una amplitud de $1200 \mathrm{nT}$. Hay otros dipolos pequeños, de los cuales, el más notable está en el extremo norte del mapa, $219000 \mathrm{~m}$ coordenada este. Hacia el sur del plutón San Jerónimo es notable la disminución en los valores de la intensidad magnética y que el polo negativo mayor está sobre aluvión que aparentemente cubre a un cuerpo diorítico. Además, se observa que los ejes de los dipolos de las anomalías magnéticas dipolares identificadas en la zona se orientan casi $\mathrm{N}$ - $\mathrm{S}$ con su polo negativo al norte, coincidiendo con la orientación del campo magnético terrestre actual, lo que sugiere que la magnetización que prevalece en los cuerpos es de tipo inducida y que al magnetizarse adoptan esa dirección.

En cuanto a los rasgos estructurales, se observan algunos lineamientos aeromagnéticos; por ejemplo, en la parte sur de la unidad gabro-diorítica y, de manera muy clara, cerca de la zona donde los plugs de tonalita la intrusionan. En esa zona, la elongación de los isocontornos magnéticos es casi E - W, que coincide con las tendencias estructurales de fracturas y foliación en la unidad gabro-diorítica (Figura 7a y 7b).

Para complementar el análisis cualitativo de las anomalías magnéticas, se elaboraron los perfiles geológicomagnéticos A - A', B - B' y C - C' (Figura 10). El perfil magnético-geológico A - A' de la Figura 11a muestra que el alto magnético más pronunciado $(600 \mathrm{nT})$ coincide con el afloramiento de un dique de fierro. Hacia el sur se observa una pequeña anomalía dipolar que podría generarse por efecto topográfico, o bien deberse a otro dique de óxidos de fierro no aflorante. Hacia el extremo sur del mismo perfil A - A', donde los sedimentos sepultan a las rocas intrusivas, la respuesta magnética también disminuye. En el perfil B - B' (Figura 11b) se observa una buena correspondencia

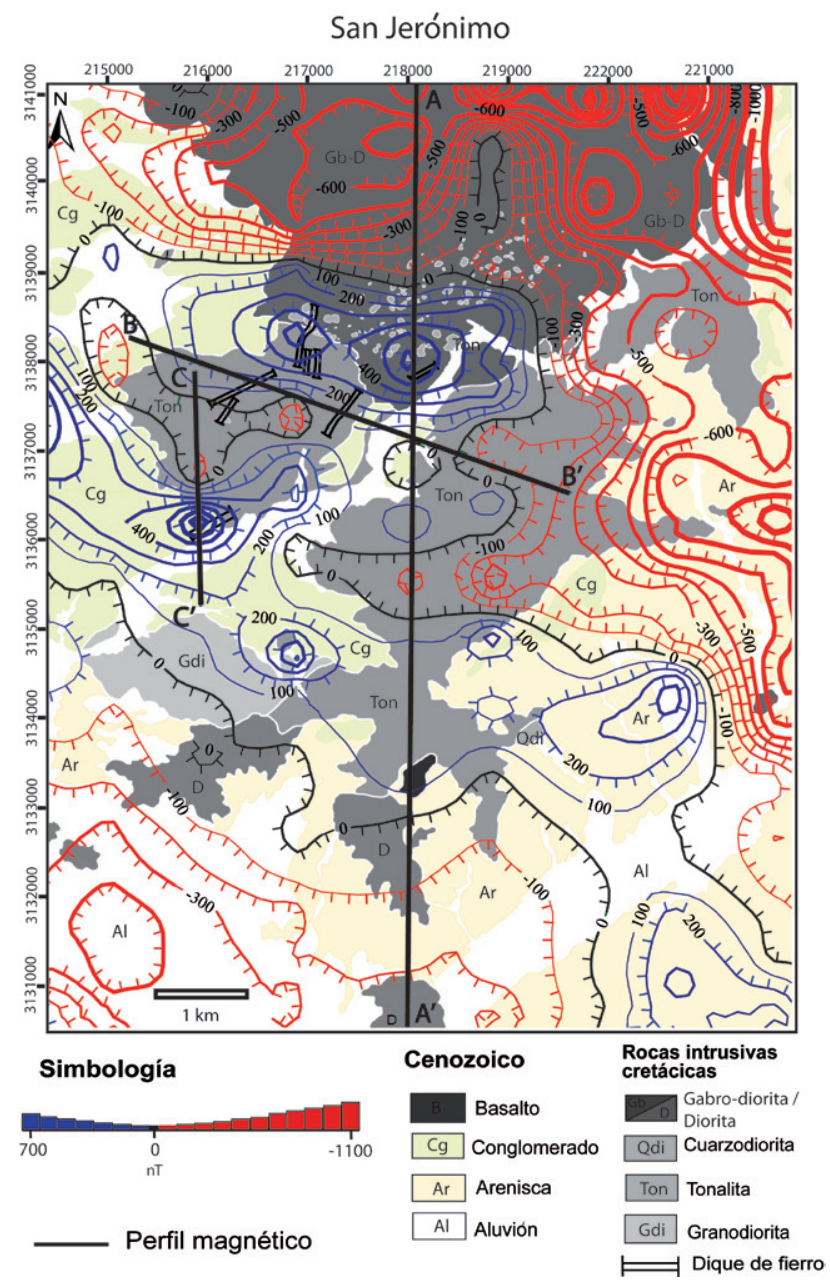

Figura 10. Contornos de intensidad de campo magnético sobrepuestos a la litología. Los contornos están a cada 100 nT. Se muestra la ubicación de los perfiles.

entre los altos magnéticos más pronunciados y la presencia de diques de óxidos de fierro. Es importante notar que la inclinación atribuida a los diques de fierro es paralela a la foliación observada en la tonalita encajonante.

Con el propósito de realizar una interpretación cuantitativa, se eligió una pequeña anomalía en la zona donde afloran diques de óxidos de fierro, sobre la que se trazó un perfil magnético (C - C'; Figura 10). En ese perfil se observa una anomalía dipolar con una amplitud cercana a los $800 \mathrm{nT}$ y una anchura aproximada de 800 m. La interpretación de la anomalía se realizó mediante modelado directo bidimensional tipo Talwani (Cooper, 2006), utilizando los siguientes parámetros del campo geomagnético: inclinación (I) $=54^{\circ} 24^{\prime}$, declinación (D) $=11^{\circ} 36^{\prime}$ e intensidad $(\mathrm{To})=45790 \mathrm{nT}$. En el modelo se consideró que la anomalía se debe a la presencia del dique de óxidos de fierro encajonado en un cuerpo de tonalita cuya susceptibilidad magnética es baja. Un modelo realista basado en las observaciones de campo supone un cuerpo similar a una cuña, cuyo emplazamiento es forzado según 

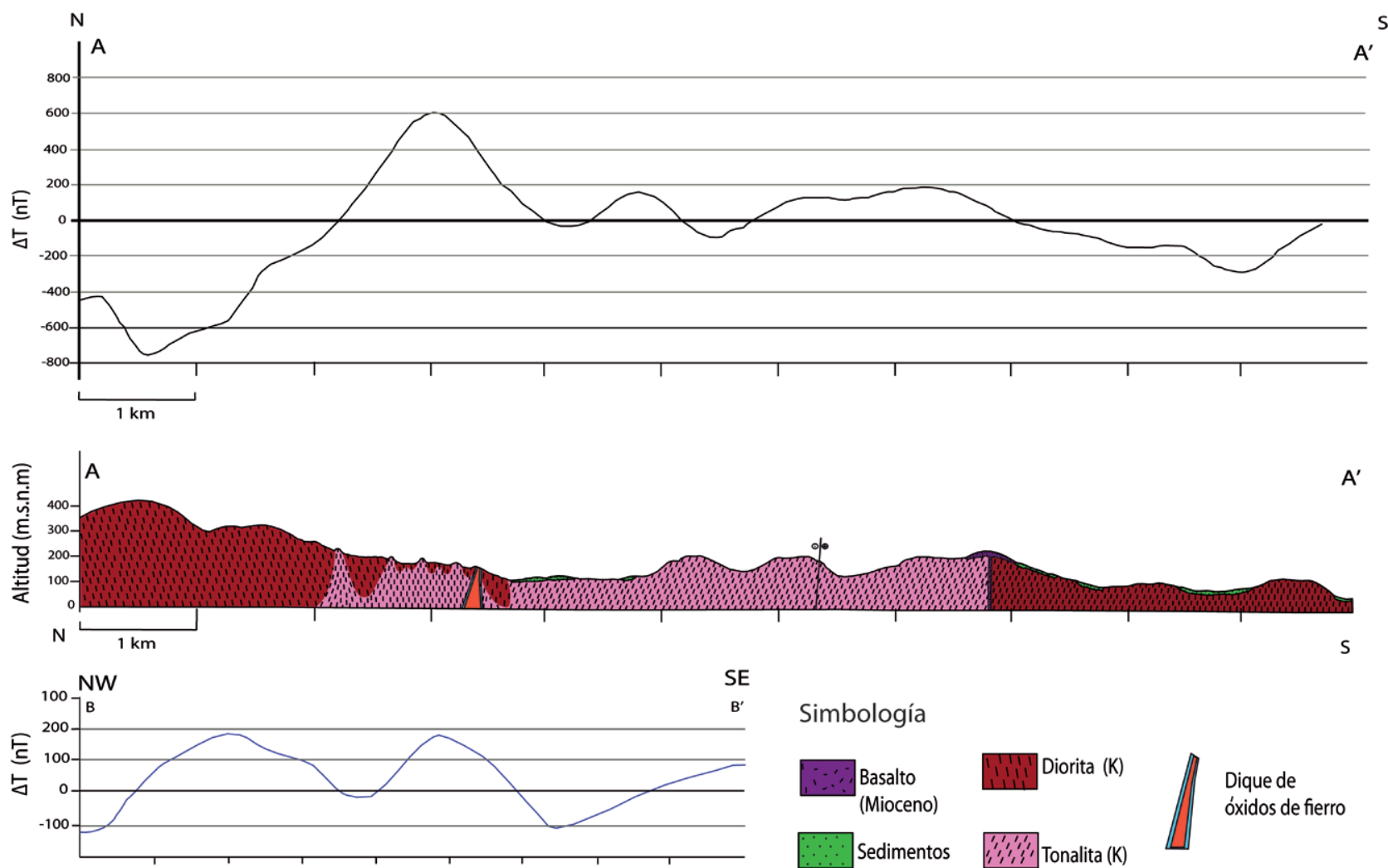

Simbología
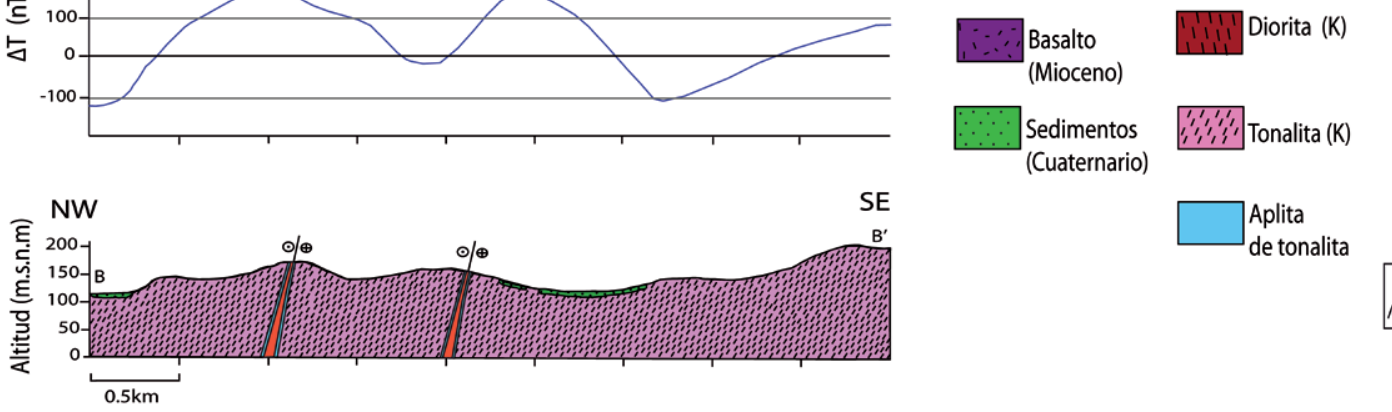

Dique de óxidos de fierro

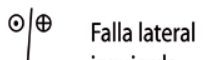

izquierda

Valores observados de campo magnetica

Figura 11. A y B son secciones donde se integra la información estructural y los perfiles de intensidad del campo magnético del plutón San Jerónimo. La dirección de las líneas del achurado en rocas intrusivas representa la inclinación de la foliación. La ubicación de los perfiles está en la Figura 10.

indican las estrías en sus costados. La susceptibilidad magnética medida en una muestra de este cuerpo es de 143.4 x $10^{-3} \mathrm{SI}$, menor al valor máximo obtenido en el laboratorio para el conjunto de las muestras de diques de óxidos de fierro $\left(160 \times 10^{-3} \mathrm{SI}\right)$. Del modelo resulta que el cuerpo causante de la anomalía es un prisma que aflora en la superficie cuya inclinación hacia el norte, profundiza aproximadamente hasta los $500 \mathrm{~m}$ (Figura 12) y su longitud es de $340 \mathrm{~m}$. La susceptibilidad magnética asignada a la tonalita que encajona a este dique de fierro es de $6.0 \times 10^{-3} \mathrm{SI}$.

\section{Discusión}

De acuerdo con la proporción de rocas máficas/félsicas, así como por la mineralogía de las rocas máficas, el plutón San Jerónimo puede dividirse en una zona dominada por rocas diorítico-gabróicas, donde el contenido de magnetita diseminada es alto y las concentraciones de óxidos de fierro pueden formar depósitos de interés económico; y otra, localizada hacia el sur del área de estudio, donde las rocas máficas y félsicas se distribuyen aproximadamente en la misma proporción y aparecen rocas más silícicas con un contenido de magnetita notablemente menor. La distribución de rocas representativas en el diagrama QAP muestra una variación gradual desde gabro-diorita (aproximadamente Q0A0P100) hasta tonalita (aproximadamente Q40A0P60), desde donde los magmas se enriquecen en feldespato potásico hasta alcanzar el campo del granito. En este diagrama las rocas de las dos zonas son indistinguibles.

A diferentes escalas se observa que los lineamientos, la foliación magmática, fracturas primarias y los diques guardan relaciones geométricas entre sí. Se interpreta que los lineamientos curvilíneos se asocian a pulsos verticales de magma. Bajo esa premisa el esfuerzo principal máximo es perpendicular al contorno de una cámara magmática en expansión y el esfuerzo principal mínimo es aproximadamente paralelo a las isotermas del reservorio magmático. En ese sentido, las fracturas longitudinales verticales y la foliación magmática, deben guardar una relación estrecha. En el PSJ dicha relación es consistente pues ambos sistemas se orientan preferencialmente en 


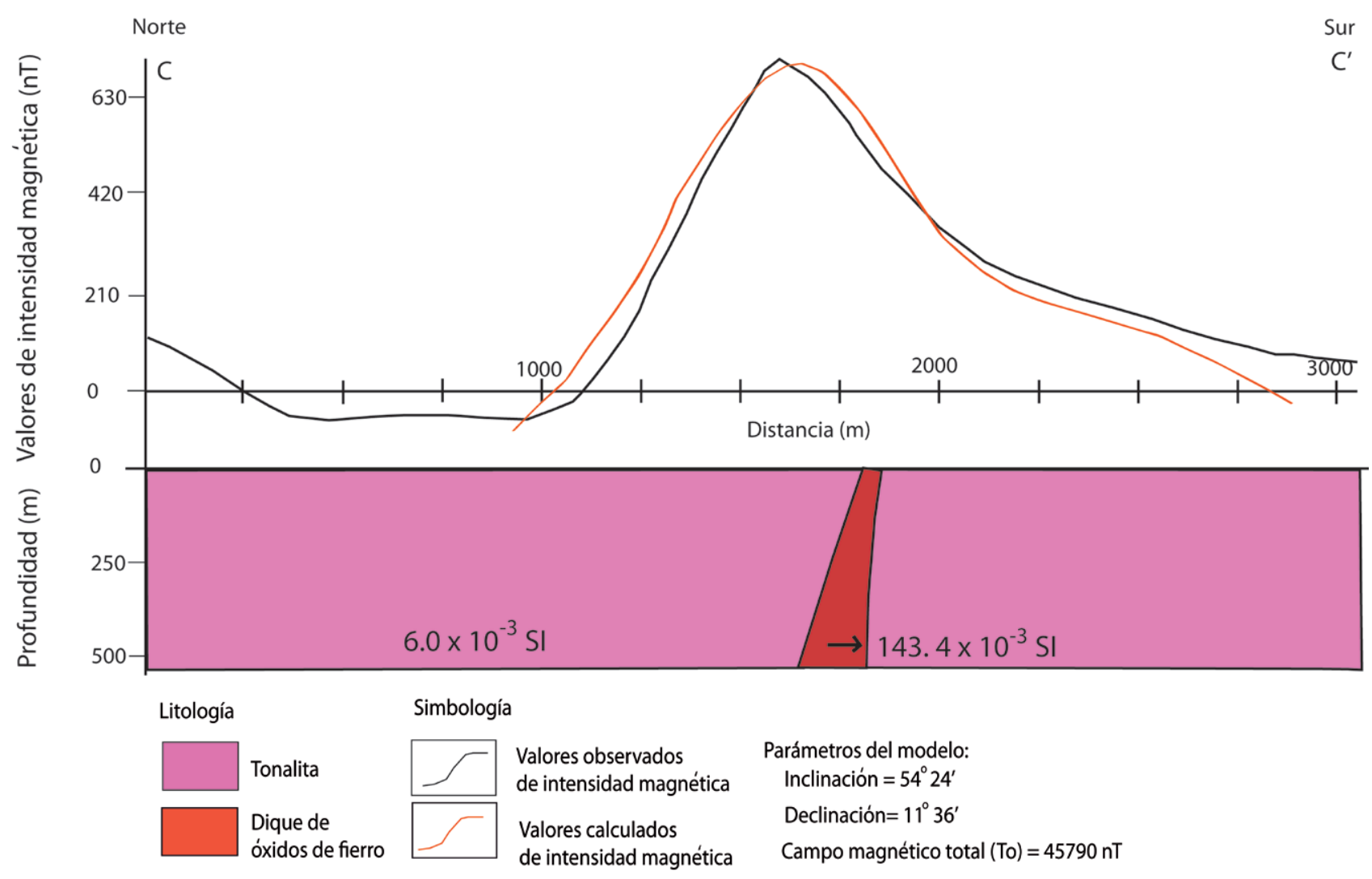

Figura 12. Modelo del perfil magnético C-C'. En la parte superior se compara la respuesta del modelo con el perfil magnético observado. Hacia el sur del perfil se infiere la existencia de tonalita, la cual se encontraría por debajo de una capa delgada de sedimentos de acuerdo con el mapa de la Figura 10.

dirección NE - SW que, a su vez, indicaría la dirección principal del emplazamiento de los plutones discretos y anidados.

De lo anterior se desprende que es altamente probable que los diferentes momentos de emplazamiento del PSJ, tanto de los cuerpos máficos como de los félsicos, hayan estado espacialmente controlados por la presencia de estructuras regionales orientadas NE - SW. Los rasgos curvilíneos en el cuerpo gabróico-diorítico de la zona norte son notablemente escasos, lo cual se explica al considerar que los magmas máficos en estado fundido a temperaturas del orden de los $1200^{\circ} \mathrm{C}$ tienen una viscosidad aproximada que puede ser tan baja como $0.41 \mathrm{~Pa} \cdot \mathrm{s}$, que contrasta notablemente con la de los magmas félsicos, los que a 900 ${ }^{\circ} \mathrm{C}$ alcanzan una viscosidad aproximada de $1.0 \mathrm{~Pa} \bullet$ s (Spera, 2000), cuestión discutida ampliamente por Torres-Carrillo (2010). De acuerdo con lo anterior, dicha viscosidad propicia que en los magmas máficos las velocidades de ascenso sean mayores que en un magma félsico y, como resultado, su emplazamiento tienda a ser rápido y uniforme. En ese orden de ideas, las estructuras anidadas debidas al emplazamiento de magma en pulsos periódicos no se desarrollan con la misma facilidad en las rocas máficas como en las félsicas. Una evidencia adicional a favor del emplazamiento de pulsos homogéneos de masas grandes de magma máfico se desprende del análisis de las fracturas y la foliación, las cuales presentan un arreglo ortogonal con echados mayores a $75^{\circ}$ correspondientes a plutones que se han emplazado verticalmente en estructuras de aspecto columnar o cilíndrico, bajo procesos de emplazamiento similar al diapírico, esto es, por efecto de contraste de densidad. En el mismo sentido, Torres-Carrillo (2010) reporta la presencia de texturas poikilíticas en las rocas diorítico-gabróicas que apuntan en la misma dirección, pues su frecuencia en estas rocas sugiere condiciones de estabilidad que resultan de pulsos magmáticos grandes con gradientes de temperatura pequeños.

Se interpreta que los diques de óxidos de fierro, cuya composición mineralógica característica es $\mathrm{Mt}>\mathrm{Qz}>$ $2 \mathrm{Px}>\mathrm{Ap}$, están genéticamente relacionados con la unidad gabro-diorítica. De acuerdo con Duchesne (1999), la existencia de cuerpos masivos de fierro en otras regiones se ha interpretado como producto de inmiscibilidad líquida. Por su parte, Philpotts (1967) y Lindsley (1991) mencionan que para que una separación de este tipo exista, el escenario posible requiere de la presencia de fósforo en el magma, pues éste baja la temperatura de fusión del líquido, aumenta la solubilidad de los óxidos en el líquido silicatado e inhibe la saturación de minerales de óxido de $\mathrm{Fe}-\mathrm{Ti}$. En consecuencia, la concentración de $\mathrm{P}$ permite que el Fe y el 
Ti se concentren hasta niveles suficientemente altos para dar como resultado un líquido inmiscible a temperaturas entre $1010^{\circ} \mathrm{C}$ y $1040{ }^{\circ} \mathrm{C}$ (Veksler et al., 2006) o entre $1050{ }^{\circ} \mathrm{C}$ y $1190^{\circ} \mathrm{C}$ (Bogaerts y Schmidt, 2006). Nótese que ambos rangos de temperatura son inferiores a los propuestos para el emplazamiento en estado fundido de los cuerpos máficos. En el PSJ, el proceso de inmiscibilidad debió ocurrir a temperaturas similares a las mencionadas arriba en una etapa temprana de cristalización del fundido; en estas condiciones el líquido rico en Fe continuó como un cuerpo aislado durante todo el proceso de cristalización.

En muchos de los respaldos de los diques de óxidos de $\mathrm{Fe}$, es común que diques tonalíticos (plugs) presenten texturas aplíticas que indican gradientes de temperatura grandes que pueden deberse a la rápida pérdida de calor del magma en ascenso (tonalita) al ponerse en contacto con superficies preexistentes más frías y sólidas, en este caso de los cuerpos de Fe. Estas aplitas tonalíticas, están asociadas a su vez con cuerpos más grandes de la misma composición que forman series de diques pequeños de aspecto circular (plugs) alineados NE - SW y que intrusionan a la unidad gabro-diorítica. Se identificaron zonas de mezcla de tonalita penetrando en diorita en la zona con mayor densidad de plugs, por lo que se interpreta que el magma félsico se emplazó a lo largo de fracturas de extensión, principalmente verticales, desarrolladas por enfriamiento en la zona de frontera de la masa gabro-diorítica. Lo anterior implicaría que dichos plugs, de aspecto circular, estuvieran unidos a profundidad y formaran un dique de cerca de $1 \mathrm{~km}$ de anchura según la exposición superficial de los plugs y el arreglo paralelo que guardan con la orientación de las fracturas verticales. Estructuras activas similares han sido reportadas en distintos lugares (por ejemplo en el volcán Miyakejima, Japón; Furuya et al., 2003).

De la relación espacial entre las aplitas y los diques de óxidos de fierro, junto con las evidencias de cizalla lateral izquierda en estos dos tipos de roca orientadas hacia el $\mathrm{NE}$ - SW, se infiere que el emplazamiento de los diques de fierro está promovido por el empuje y lubricación proporcionado por el emplazamiento del magma tonalítico; el emplazamiento forzado de los cuerpos de fierro, en estado semisólido, pudo grabar la fricción en forma de superficies estriadas que indican de manera consistente la dirección del emplazamiento con dirección NE - SW, casi paralela a la dirección dominante de las foliaciones en la tonalita y a las fracturas verticales en ese mismo tipo de roca. Además, también es notable que el echado de los diques de fierro concuerde con los planos de foliación de la tonalita, por lo que se interpreta el desarrollo simultáneo de las cizallas con el empuje ascendente del magma tonalítico.

Las diferencias entre los cuerpos plutónicos gabrodioríticos del norte y los intrusivos I, II y III del sur también se manifiestan en la respuesta magnética de las rocas. La intensidad de las anomalías magnéticas es notablemente mayor en el norte que en el sur. De acuerdo con la propuesta de Breiner (1999), la capacidad de magnetizarse de un cuerpo está relacionada con el contenido de minerales magnéticos $\mathrm{y}$, por consiguiente, con sus valores de susceptibilidad magnética. En la zona norte, donde se observan los cuerpos con más alta susceptibilidad magnética y los diques de Fe, tanto el contenido de minerales ferromagnéticos, como de opacos, son altos. En consecuencia, los altos magnéticos principales tienen correspondencia con la presencia de diques de óxidos de fierro que afloran en la parte central del área de estudio.

\section{Conclusiones}

Se observa una relación directa entre el contenido alto de óxidos de fierro, los valores altos de susceptibilidad, la respuesta del campo magnético total y la composición gabro-diorítica de las unidades litológicas del plutón San Jerónimo.

Los lineamientos estructurales curvilíneos se generan a partir de pulsos verticales mientras que las fracturas longitudinales verticales y la foliación magmática guardan una relación estrecha y se orientan NE - SW, según la dirección principal del emplazamiento de los plutones, tanto discretos como anidados.

Se interpreta que en la masa gabro-diorítica, por inmiscibilidad líquida, ocurrió la separación de óxidos de fierro, cuya composición mineralógica característica en los diques es $\mathrm{Mt}>\mathrm{Qz}>2 \mathrm{Px}>\mathrm{Ap}$. Su posterior emplazamiento, en estado sólido, se debió al empuje que le imprimió el movimiento ascendente y con componente hacia el NE del magma tonalítico, del que derivan las aplitas que encajonan a los diques de óxidos de fierro.

\section{Agradecimientos}

Este trabajo ha sido realizado gracias a los fondos del proyecto CONACyT 45817 concedido a L.A.D.A. Agradecemos el apoyo recibido por técnicos, investigadores y compañeros estudiantes de la División de Ciencias de la Tierra del CICESE: Luis Gradilla nos apoyó con los análisis de microscopía electrónica; Víctor Pérez elaboró las láminas delgadas; Gabriel Rendón colaboró con la aplicación de técnicas para el análisis petrográfico; Edgardo Cañón abrió las puertas de su laboratorio para medir la susceptibilidad magnética; Porfirio Avilez ayudó en el trabajo de campo. José de Jesús Rodríguez Salinas por el apoyo brindado durante la búsqueda de los datos aeromagnéticos del SGM. Bodo Weber y Felipe Escalona hicieron importantes aportaciones al manuscrito. Agradecemos finalmente las revisiones cuidadosas y estrictas de Roberto Molina y Gabriel Chávez pues, gracias a ellas, este manuscrito mejoró notablemente. 


\section{Referencias}

Bogaerts, M., Schmidt, M.W., 2006, Experiments on silicate melt immiscibility in the system $\mathrm{Fe}_{2} \mathrm{SiO}_{4}-\mathrm{KAlSi}_{3} \mathrm{O}_{8}-\mathrm{SiO}_{2}-\mathrm{CaO}-\mathrm{MgO}-$ $\mathrm{TiO}_{2}-\mathrm{P}_{2} \mathrm{O}_{5}$ and implications for natural magmas: Contribution to Mineralogy and Petrology, 152, 257-274.

Breiner, S., 1999, Applications Manual for Portable Magnetometers: San Jose, California, Geometrics, $58 \mathrm{p}$.

Cooper, G.R.J., 2006, Interpreting potential field data using continuous wavelet transforms of their horizontal derivatives: Computers and Geosciences, 32, 984-992.

Chávez-Cabello, C.G., 1998, Mecanismos de ascenso, emplazamiento y evolución magmática de varios plutones al oeste de la sierra San Pedro Mártir, Baja California, México: Ensenada, Baja California, Centro de Investigación Científica y de Educación Superior de Ensenada (CICESE), tesis de maestría, $127 \mathrm{p}$.

Delgado-Argote, L.A., López-Martínez, M., Pérez-Flores, M.A. and Fernández-Tomé, R., 1995, Emplacement of the nucleus of the San Telmo Pluton, Baja California, from geochronologic, fracture and magnetic data, en Jacques-Ayala, C., González-León, C.M., RoldánQuintana, J. (eds.), Studies on the Mesozoic of Sonora and Adjacent Areas (Geological Society of America Special Paper 301): Boulder, Colorado, Geological Society of America, 191-204.

Delgado-Argote, L.A., Camarena-García, M.A., Peña-Alonso, T.A., Weber, B., Molina, R., Böhnel, H., 2006, Inferencias sobre el emplazamiento regional de complejos plutónicos en Baja California central a través de indicadores estructurales: Geos, 26, 65.

Delgado-Argote, L.A., Peña Alonso, T.A., Torres Carrillo, X.G., Avilez Serrano, P., 2009, Ambientes de emplazamiento y características geoquímicas de los complejos plutónicos del margen SW del Cinturón Batolítico Peninsular, Baja California, México: Geos, $29,69$.

Duchesne, J.C., 1999, Fe-Ti deposits in Rogaland anorthosites (South Norway): geochemical characteristics and problems of interpretation: Mineralium Deposita, 34, 182-198.

Furuya, M., Okubo, S., Sun, W., Tanaka, Y., Oikawa, J., 2003, Spatiotemporal gravity changes at Miyakejima Volcano, Japan: Caldera collapse, explosive eruptions and magma movement: Journal of Geophysical Research, 108, 221.

Gastil, R.G., 1983, Mesozoic and Cenozoic granitic rocks of Southern California and Western Mexico, en Roddick, J.A. (ed.), Circumpacific Plutonic Terranes (Geological Society of America Memoir 159): Boulder, Colorado, Geological Society of America, 265-275.

Gastil, R.G., Phillips, R.P., Allison, G.C., 1975, Reconnaissance Geology of the State of Baja California (Geological Society America Memoir 140): Boulder, Colorado, Geological Society of America, $170 \mathrm{p}$.

Gastil, R.G., Diamond, J., Knaack, Ch., Wallawander, M., Marshall, M., Boyles, C., Chadwick, B., Erskine, B., 1990, The problem of the magnetite/ilmenite boundary in southern and Baja California, en Anderson, J.L. (ed.), The Nature and Origin of Cordilleran Magmatism (Geological Society of America Memoir 174): Boulder, Colorado, Geological Society of America, 19-32.

Gromet, P.L., Silver, L.T., 1987, REE Variations Across the Peninsular Ranges Batholith: Implications for Batholithic Petrogenesis and Crustal Growth in Magmatic Arcs: Journal of Petrology, 28, 75-125.

Hibbard, M.J., 1995, Petrography to Petrogenesis: Englewood Cliffs, Nueva Jersey, Prentice-Hall, $587 \mathrm{p}$.

Kimbrough, D.L., Smith, D.P., Mahoney, J.B., Moore, T.E., Groove, M., Gastil, R.G., Ortega Rivera, A., Fanning, C.M., 2001, Forearc sedimentary response to rapid Late Cretaceous batholith emplacement in the Peninsular Ranges of southern and Baja California: Geology, 29, 491-494.

Le Maitre, R.W., 2002, Igneous Rocks: A classification and glossary of terms: Cambridge, Reino Unido, Cambridge University Press, 236 p.

Lindsley, D.H., 1991, Origin of Fe-Ti oxide deposits in the Laramie anorthosite complex (resumen), en IGCP 290 Adirondack Meeting: Hamilton, Nueva York, International Geological Correlation Programme, 23, 257-290.
Marsh, B.D., 2000, Magma chambers, en Sigurdsson, H. (ed.), Encyclopedia of Volcanoes: San Diego, California, Academic Press, 191-205.

Phillips, W.J., 1974, Hydraulic fracturing and mineralization: Journal Geological Society of London, 128, 337-359.

Philpotts, A.R., 1967, Origin of certain iron-titanium oxide and apatite rocks: Economic Geology, 62, 303-315.

Price, N.J., Cosgrove, J.W., 1991, Analysis of Geological Structures: Nueva York/Cambridge, Cambridge University Press, Cambridge, 502 p.

Schmidt, K.L., Wetmore, P.H., Johnson, S.E., Paterson, S.R., 2002, Controls on orogenesis along an ocean-continent margin transition in the Jura-Cretaceos Peninsular Ranges batholiths, en Barth, A. (ed.), Contributions to Crustal Evolution of the Southwestern United States (Geological Society of America Special Paper 365): Boulder, Colorado, Geological Society of America, 49-71.

Servicio Geológico Mexicano (SGM), 2003, Datos aeromagnéticos digitales contenidos en la hoja H11-12 (Isla Cedros): Pachuca, Hidalgo, Servicio Geológico Mexicano, CD-ROM.

Sharma, P.V., 1976, Geophysical Methods in Geology: Nueva York, Elsevier Scientific Publishing Company, $429 \mathrm{p}$.

Silver, L.T., Chappell, B.W., 1988, The Peninsular Ranges Batholith: an insight into the evolution of the Cordilleran batholiths of southwestern North America: Transactions of the Royal Society of Edinburgh Earth Sciences, 79, 105-121.

Silver, L.T., Taylor, H.P., Chapell, B., 1979, Some petrological, geochemical and geochronological observations of the Peninsular Ranges batholith near the international border of the U.S.A. and Mexico, en Abbott, P.L., Todd, V.R. (eds.), Mesozoic Crystalline Rocks: Peninsular Ranges Batholith and Pegmatites, Point Sal Ophiolite; Geological Society of America Annual Meeting Guidebook: San Diego, California, San Diego State University Department of Geological Sciences, 83-110.

Sinton, J.M., Langmuir, C. H., Bender, J.F., Detrick, R.S.D., 1992, What is a magma chamber?: RIDGE Events, 3, 46-49.

Spera, J.F., 2000, Physical properties of magmas, en Sigurdsson, H. (ed.), Encyclopedia of Volcanoes: San Diego, California, Academic Press, 171-190.

Symons, D.T.A., Walawender, M.J., Smith, T.E., Molnar, S.E. Harris, M.J., Blackburn, W.H., 2003, Paleomagnetism and geobarometry of the La Posta pluton, California, en Johnson, S.E., Paterson, S.R., Fletcher, J.M., Girty, G.H., Kimbrough, D.L., Martín-Barajas, A. (eds.), Tectonic Evolution of Northwestern Mexico and the Southwestern USA (Geological Society of America Special Paper 374): Boulder, Colorado, Geological Society of America, 135-155.

Tarling, D.H., 1967, The paleomagnetic properties of some Tertiary lavas from East Greenland: Earth and Planetary Science Letters, 3, 81-88.

Torres-Carrillo, X.G., 2010, Análisis geológico del complejo plutónico San Jerónimo, al sur del Cinturón Batolítico Peninsular, Baja California, México: Ensenada, Baja California, Centro de Investigación Científica y de Educación Superior de Ensenada (CICESE), tesis de maestría, $107 \mathrm{p}$.

Veksler, I.V., Dorfman, A.M., Danyushevsky, L.V., Takobsen, J.K., Dingwell, D.B., 2006, Immiscible silicate liquid partition coefficients: implications for crystal-melt element partitioning and basalt petrogenesis: Contribution to Mineralogy and Petrology $152,685-702$.

Manuscrito recibido: Septiembre 14, 2011.

Manuscrito corregido recibido: Septiembre 18, 2011.

Manuscrito aceptado: Septiembre 18, 2011. 